\title{
Research on the Influence Mechanism of Role Overload on Entrepreneurial Burnout -- Use SEM structural equation and SPSS software
}

\author{
Chang $\mathrm{Li}^{1}$, Chen Fei Meng ${ }^{2}$, and Hong Li Chen ${ }^{3}$ \\ ${ }^{1}$ The Department of Business Administration, Zhejiang Gongshang University School, Hangzhou, Zhejiang Province, China
}

\begin{abstract}
Entrepreneurial burnout is a common practical problem faced by entrepreneurs under the pressure of multiple roles. Drawing on theory related to self-identity and conservation of resource, this study reveals the mechanism between role overload and entrepreneurial burnout, as well as the moderating effect of perceived social support. We used SEM structural equations to test the main effects, and Bootstrap repeated sampling was used to estimate the indirect effects and their sampling distribution. At the same time, multiple regression analysis was carried out using Process to test the regulatory effect.The results show that role overload is positively correlated with burnout, obsessive passion plays a mediating role, and perceived social support plays a moderating role.
\end{abstract}

\section{Introduction}

Due to the short time of establishment and the lack of sufficient funds, start-up enterprises are generally faced with difficulties such as lack of resources, small scale and high business risk. Meanwhile, entrepreneurs need to play multiple roles in the management and operation activities of the enterprise. Therefore, entrepreneurs are generally faced with heavy tasks and time constraints in the process of starting a business. When entrepreneurs do not have enough time and resources to meet the work needs of multiple roles, it is easy to lead to role overload and cognitive overload, resulting in burnout. Empirical evidence shows that if entrepreneurs face burnout and are unable to deal with it, they may question their commitment to their business and withdraw from subsequent entrepreneurial activities, which can have a negative impact on their business and the future growth of the company. Therefore, it is very important to understand the mechanism of entrepreneur burnout, including the mediating mechanism and regulating effect, to solve the problem of entrepreneur burnout.

Previous literature has focused on employee burnout as a result of the stress inherent in many occupations ${ }^{[1]}$. However, traditional predictors of burnout, such as employees' need for autonomy, experiential leadership styles and roles, and freedom to modify role descriptions, are not appropriate for an entrepreneurial environment. Entrepreneurs is regarded as a special professional group, compared with the general organization, entrepreneurs more complex environment and working conditions, more is not regular, so the entrepreneurs in the process of entrepreneurship need higher job control and job requirements, including quickly adapt to the change of business environment, bear the huge workload, facing the unpredictable environment, and have high sense of responsibility for others, etc ${ }^{[2]}$. Once the entrepreneur cannot bear these pressures or lack of corresponding resources, it will bring negative emotional experience to the entrepreneur. Therefore, the usual methods of measuring occupational stress can not be effectively applied to entrepreneurs. In order to better explain the phenomenon that entrepreneurs are more likely to feel burnout than ordinary employees, existing studies have explored the influencing factors of entrepreneurial burnout, mainly focusing on job requirements, entrepreneurial pressure and social responsibility. Some scholars put forward role overload is likely to be entrepreneurial burnout before because of role overload the direct impact can bring more tired to entrepreneurs, and reduces the energy and vitality of the entrepreneur, but so far about the role of entrepreneurial environment overloading, especially for the role overload and entrepreneurship burnout and the mechanism of action between them are relatively $\operatorname{lack}^{[3]}$. Therefore, the purpose of this study is to explore why some people engaged in entrepreneurial work are more prone to burnout than others, and what is the mechanism of its formation? How can ability alleviate the tiredness of entrepreneur.

Based on the theory of identity and the theory of resource conservation, this paper proposes a mediating model of the effect of entrepreneur role overload on entrepreneurial burnout. Compulsive passion is introduced to explain the mechanism of the effect of entrepreneur role overload on entrepreneurial burnout, and the moderating effect of perceived social support. We find that role overload of entrepreneurs has an

\footnotetext{
*Chen Fei Meng: 958961570@qq.com
} 
impact on entrepreneurial burnout through the transmission of compulsive passion, and the higher the degree of perceived social support, the weaker the impact of obsessive passion of entrepreneurs on entrepreneurial burnout. The main contributions of this paper are as follows: firstly, role overload is taken as an antecedent variable to provide a new explanation for the influence mechanism of entrepreneurial burnout; Second, we demonstrate that passion is two-sided, and that forcing it can lead to burnout for entrepreneurs. Finally, this paper proposes the perceived social support as a moderating variable to alleviate entrepreneurial burnout, to a certain extent, to help entrepreneurs recognize their own social resources, and learn to self-regulate under entrepreneurial pressure, which has important enlightenment significance for entrepreneurs to maintain physical and mental health.

\section{Theory and Hypothesis}

\subsection{Role overload and entrepreneurial burnout}

Entrepreneur in the founding and development of new enterprises often need to play multiple roles, when faced with a series of problems such as time, shortage of resources, or from volume ${ }^{[5]}$, especially the high strength work, lead to role overload, when individuals in the case of limited time and limited resources, to take on more work requirements, complete the various tasks can produce role overload, not good for your goal and personal development.

The most commonly used definition of burnout, proposed by Maslach et al. ${ }^{[1]}$, is "an occupational symptom of a persistent level of emotional stress resulting from an inability to adapt the individual to the work environment". Startup burnout is one of the results of the interaction of "entrepreneurial environment". It is a syndrome formed by entrepreneurs under long-term work pressure, which is a kind of physical, mental and emotional exhaustion. In the process of entrepreneurship, entrepreneurial burnout has a significant impact on enterprise performance and entrepreneurial success ${ }^{[4]}$.

According to the resource conservation theory ${ }^{[3]}$, great stress can severely drain an individual's energy and resources. Previous studies have found that when individual resources are not compensated in time, individual negative emotional responses will be triggered, leading to job burnout ${ }^{[5]}$. The multiple roles in the process of entrepreneurship, entrepreneur, there was a role overload when entrepreneurs, entrepreneurs will overdraw their physical and mental resources to complete the task requires too much or too much, resulting in the individual pays resources are often in the case of a restoration is used up, so entrepreneurs don't have enough resources to deal with increasing pressure, after finally due to the limited resources and produce entrepreneurial burnout. The research of Shepherd et $\mathrm{a}^{[2]}$. proposed that there may be a correlation between role overload and entrepreneurial burnout. In addition, some scholars believe that individuals in such an overloaded work state will experience greater pressure, which will lead to negative emotions or emotional exhaustion, and long-term such situation will lead to entrepreneurial burnout ${ }^{[6]}$. Based on the above theory, this paper proposes:

H1: There is a significant positive correlation between entrepreneur role overload and entrepreneurial burnout.

\subsection{The mediating role of compulsive passion}

Passion is a central characteristic of entrepreneur behavior, defined as a strong tendency to invest time and energy in activities that the entrepreneur enjoys and considers important. The research of Vallerand et $\mathrm{a}^{[7]}$. points out that passion can be divided into harmonious passion and compulsive passion. Compulsive passion is an uncontrollable impulse to participate in activities, which is the result of the perception and behavior of entrepreneurs ${ }^{[8]}$. Pressure sources such as role overload will constantly stimulate individual potential and competitive spirit, which not only bring multiple role pressures to entrepreneurs, but also lead entrepreneurs to participate in entrepreneurial activities in a rigid form. On the one hand, in the role of entrepreneurs under overload if failed to live up to the expectations of the specification on the identification performance, selfconcept and self-esteem will be affected, so in order to achieve character recognition and meet the requirements of multiple roles, entrepreneurs will invest a lot of time and energy to the entrepreneurial activity, and do so at the same time, led to the compulsive side of passion ${ }^{[8]}$. On the other hand, entrepreneurs do not engage in entrepreneurship voluntarily, but rather are forced to engage in entrepreneurship based on external pressures to gain identity recognition and self-esteem, thus affecting the nature of the passion that the entrepreneur fosters.

Forcing passion can lead to startup burnout through resource depletion and rigid persistence. According to the theory of resource conservation, entrepreneurs with forced passion will be forced to continuously invest resources into starting a business. Continued work pressure and consumption of personal resources will trigger negative emotional reactions of individuals, which will lead to entrepreneurial burnout. From the perspective of emotional resources, has forced the entrepreneurs of passion, when engaged in the activities of passionate, easy to obtain a higher sense of honor, the larger psychological pressure and low psychological well-being, these negative psychological produce, management and control of limited emotional resources $^{[9]}$, need to consume entrepreneurs will also increase the likelihood of entrepreneurship is tired. In other words, forced passion is a constant drain on the entrepreneur's personal resources, leading to burnout. In addition, individuals with obsessive passions internalize work and interpersonal stress in a controlled way, and in this internalization, individuals feel stressed because they do not voluntarily participate in activities ${ }^{[10]}$. Such internal compulsion leads to a rigid and conflicting form of task participation, which usually brings negative 
emotional results to entrepreneurs, such as depression, emotional exhaustion, decreased happiness, and burnout, which seriously affects the emotional experience of entrepreneurs in entrepreneurial activities. As individuals develop a rigid persistence in their work, a great deal of effort is invested and a great deal of working time is generated. However, there is less time for recovery, for example, spending less time with family than the average employee. Therefore, it is difficult for entrepreneurs to completely free themselves from thinking about entrepreneurial activities, and psychologically unable to get rid of busy work, which eventually leads to exhaustion, thus leading to entrepreneurial burnout.

Therefore, this paper puts forward the intermediary hypothesis, that is, in order to meet the role requirements and expectations, entrepreneurs are forced to invest a lot of time and energy into entrepreneurship, and form a rigid persistence. Such obsessive passion for work eventually leads to their negative emotions and entrepreneurial burnout.

$\mathrm{H} 2$ : Compulsive passion mediates the relationship between role overload and entrepreneurial burnout.

\subsection{The moderating role of perceived social support}

Social support refers to the emotional and social relationships that people receive from others as they cope with stressful events in their lives. According to resource conservation theory, social support is the most important buffer for emotional exhaustion because it can not only increase the amount of resources available to an individual, but also replace or reinforce other resources that are lacking ${ }^{[11]}$. Gottlieb and Bergen ${ }^{[12]}$ further explained perceived social support: perceived social support refers to people's beliefs about how much potential support they have in interpersonal relationships and social interactions and the quality of that support. Perceived social support is further explained as a person's perception of the availability of social networks such as family members, friends and acquaintances, as well as satisfaction with supportive relationships. Entrepreneurs through social interaction with family, friends, or others can get the needed resources and supporting social relationships, when they feel they have the support from the society of others, their psychological pressure, or tension should be reduced, which can be in a certain extent, alleviate the anxiety of entrepreneurs, strengthen his confidence in the business, so as to reduce burnout. At work, individuals with higher compulsion are more likely to be motivated by external interests, show lower self-motivation and performancebased self-esteem, and easily fall into negative emotions. In this case, the support of family, friends or others may provide resources that help alleviate negative emotions, such as making the individual feel appreciated and valued, and redefining self-worth, thereby helping the entrepreneur to get out of the frazzled work state and reduce the impact of forced passion on startup burnout ${ }^{[13]}$. Based on this, we suggest that the relationship between compulsive passion and burnout may weaken when entrepreneurs feel that family, friends, or others care about their health and facilitate their work accordingly.

H3: Perceived social support negatively moderated the mediating relationship between compulsive passion and role overload and entrepreneurial burnout.

\section{Research Design}

\subsection{Sample collection \& Variable measurement}

In this study, a number of new enterprises in Zhejiang, Anhui, Hunan and other places were sent questionnaires. The industries involved mainly included financial services, manufacturing, communication and software services, etc.A total of 368 questionnaires were collected, of which 129 were removed based on incomplete answers or non-compliance with requirements, and 239 valid questionnaires were finally obtained. By domestic and foreign literature and integration of relevant variables, this study selected the relatively mature and widely used of the scale, selected the entrepreneur role overload, force, entrepreneurial passion burnout and four perceived social support scale, and consult the opinions of the relevant professionals, revise and perfect the relevant issues on a questionnaire, make it more in line with the situation of the entrepreneur.

The role overload measurement refers to the role overload subscale in the role pressure gauge compiled by Peterson $^{[14]}$. The scale of compulsive passion uses the measurement method used by Vallerand et al. ${ }^{[7]}$, which has been widely recognized by the academic community and has become the most extensive measurement tool for studying passion. The measurement of entrepreneurial burnout combines the entrepreneurial situation in China and adopts the scale of entrepreneurial burnout of Chinese private entrepreneurs compiled by Wei Xueyan. Perceived support was measured using a 12-item multidimensional scale of perceived social support developed by Zimet et $\mathrm{al}^{[15]}$. All the four scales have good reliability and validity.

We also conducted a series of confirmatory factor analyses (CFA) to examine the convergent and discriminant validity of each variable. The factor analysis results showed that the factor loads of each topic corresponding to the latent variables of role overload, compulsive passion, perceived social support and entrepreneurial burnout were all greater than 0.5 , which indicated that the topic corresponding to each potential variable had a high representativeness. In addition, the mean variance variation AVE of each latent variable is all greater than 0.5 , indicating that several constructs involved in this study have good aggregation validity.

\subsection{Scale design and reliability}

Character overload. In order to measure role overload, we refer to the role overload subscale in the role pressure gauge prepared by us. The applicability of the scale has been verified in many countries, and many domestic 
scholars have also referred to this scale, which has good reliability. We have slightly modified the scale with a total of six items, such as "I play too many roles and take on too many responsibilities", based on the entrepreneurial context. Respondents were asked to rate five items on a scale of 1 (strongly disagree) to 5(strongly agree). Convalidating factor analysis (CFA) results of the scale $(2 / \mathrm{DF}=1.237, \mathrm{RMSEA}=0.032, \mathrm{CFI}=0.999)$ showed that all items had an acceptable load on this single factor $(>0.40)$, and the scale had an Alpha reliability coefficient of 0.917 .

Compulsive passion. In order to measure compulsive passion, we used the measurement method used by Vallerand et al., which has been widely recognized by the academic community and has become the most widely used measurement tool for studying passion. The original scale is applicable to general activities, so we revised this item and compiled it into a passion scale for entrepreneurial activities, which contains a total of 7 items, such as "the desire to work is so strong that I can't extricate myself". Respondents were asked to rate on a scale of 1 (strongly disagree) to 5(strongly agree) how they felt about the compulsion of entrepreneurship. Convalidating factor analysis (CFA) results of the scale $(2 / \mathrm{df}=2.526, \mathrm{RMSEA}=0.080, \mathrm{CFI}=0.995)$ showed that all items had an acceptable load on this single factor $(>0.40)$, and the scale's Alpha reliability coefficient was 0.936 .

Entrepreneurial burnout. Combined with the entrepreneurial situation in China, this paper adopts the scale of entrepreneurial burnout for Chinese private entrepreneurs compiled by Wei Xueyan, which has four dimensions: emotional exhaustion; Deindividuation; Entrepreneurial sense of achievement; Entrepreneurial identity. The scale consists of 20 items, such as' Working all day makes me nervous and physically exhausted '. Convalidating factor analysis (CFA) results of the scale $(2 / \mathrm{df}=1.493, \mathrm{RMSEA}=0.046, \mathrm{CFI}=0.967)$ showed that all items had an acceptable load on this single factor $(>0.40)$, and the scale's Alpha reliability coefficient was 0.917.

Perceived support. In this paper, a 12-item multidimensional perceptual social support scale developed by Zimet et al was used to measure perceptual support. The perceived support scale included factors of family support, friend support and other significant other support. The CFA results of the measurement scale $(2 / \mathrm{df}=1.438, \mathrm{RMSEA}=0.043, \mathrm{CFI}=0.996)$ showed that all items had an acceptable load on this single factor $(>0.40)$, and the scale had a good reliability with an Alpha reliability coefficient of 0.955 .

Control variables. We investigated seven control variables, measuring the respondents' gender, age, marital status, educational level, years of entrepreneurship, number of employees in the enterprise, and industry. Respondents' age and tenure were measured in years, while gender was a dichotomous variable.

\subsection{Hypothesis testing}

\subsubsection{Correlation test}

The results of mean, standard deviation and correlation of all variables showed that the correlation coefficients among variables were moderate. Role overload was positively correlated with compulsive passion $(\mathrm{r}=0.273$, $\mathrm{P}<0.01)$ and entrepreneurial burnout $(\mathrm{r}=0.352, \mathrm{P}<0.01)$. There was also a significant positive correlation between compulsive passion and entrepreneurial burnout ( $\mathrm{r}=0.306$, $\mathrm{P}<0.01$ ). The results of correlation analysis showed that the measurement tool had good validity, which laid a foundation for subsequent hypothesis testing.

\subsubsection{Effects of independent variables and intermediate variables were tested}

SEM to test hypotheses, we use structure equation to test hypothesis 1 and assumption 2, because of limited sample size in this study, we also use the Bootstrap method to test hypotheses 2 -- forced mediation the entrepreneur role overload and entrepreneurial passion burnout and the relationship between the indirect role overload by forcing to the entrepreneurial passion burnout effect is significantly different from zero, the Bootstrap method is to estimate indirect effect through repeated sampling and sample distribution, and distribution to estimate the confidence interval of indirect effect. The path test results are shown in Table 1. Then we set Bootstrap resampling to 5000 times and the results obtained are shown in Table 2.

Table 1. Road test

\begin{tabular}{|c|c|c|c|c|}
\hline The path & B & S.E. & C.R. & P \\
\hline $\begin{array}{c}\text { Role overload } \rightarrow \text { compulsive } \\
\text { passion }\end{array}$ & .260 & .061 & 4.243 & $* * *$ \\
\hline $\begin{array}{c}\text { compulsive passion } \rightarrow \\
\text { entrepreneurial burnout }\end{array}$ & .201 & .061 & 3.281 & $* * *$ \\
\hline $\begin{array}{c}\text { Role overload } \rightarrow \text { entrepreneurial } \\
\text { burnout }\end{array}$ & .238 & .055 & 4.293 & $* * *$ \\
\hline
\end{tabular}

Table 2. Bootstrap mediation test

\begin{tabular}{|c|c|c|c|c|c|c|c|c|}
\hline \multirow{3}{*}{ test } & \multirow{2}{*}{$\mathrm{SE}$} & \multirow{2}{*}{$\begin{array}{c}\text { Effe } \\
\text { ct }\end{array}$} & \multicolumn{3}{|c|}{ Bias-corrected $95 \% \mathrm{CI}$} & \multicolumn{3}{|c|}{ Percenntile 95\%CI } \\
\hline & & & $\begin{array}{c}\text { Lowe } \\
\mathrm{r}\end{array}$ & $\begin{array}{l}\text { Uppe } \\
\mathrm{r}\end{array}$ & $\mathrm{P}$ & $\begin{array}{c}\text { Lowe } \\
\mathrm{r}\end{array}$ & $\begin{array}{l}\text { Uppe } \\
\text { r }\end{array}$ & $\mathrm{P}$ \\
\hline & .033 & .077 & .027 & .158 & $\begin{array}{c}* * \\
*\end{array}$ & .025 & .152 & $\begin{array}{c}* * \\
*\end{array}$ \\
\hline
\end{tabular}

With the support of Hypothesis 1, we found that role overload was significantly positively correlated with entrepreneurial burnout $(\mathrm{B}=0.230, \mathrm{P}<0.01)$. Hypothesis 2 was also verified. Role overload was significantly positively correlated with obsessive passion $(B=0.260, P$ $<0.01$ ), and obsessive passion was significantly positively correlated with entrepreneurial burnout ( $\mathrm{B}=0.201, \mathrm{P}<0.01)$. According to the Bootstrap results, role overload has a significant indirect effect on entrepreneurial burnout, with a value of $0.077(\mathrm{P}<0.05$, 
Bia-corrected $\mathrm{CI}=[0.027,0.158])$. In the mediating effect test, $95 \%$ confidence interval does not contain 0 , indicating that compulsive passion plays a significant mediating role overload and entrepreneurial burnout, which supports Hypothesis 2.

\subsubsection{The effect of moderating role}

For Hypothesis 3, we use regression based path analysis to estimate and detect interactions and conditional indirect effects. In order to test the moderating effect of perceptual support in the overall model on the effect of compulsive passion on entrepreneurial burnout, we conducted multiple regression analysis using Process. Firstly, a model was established in which the interaction between obsessive passion and perceived support affected entrepreneurial burnout to varying degrees. The results are shown in Tables 3 and 4.

Table 3. Compulsive passion $\times$ perceptual support

\begin{tabular}{|c|c|c|c|c|}
\hline Predictor variable & Coeff & $\mathrm{SE}$ & $\mathrm{t}$ & $\mathrm{P}$ \\
\hline Constant & 2.873 & .221 & 12.989 & $* * *$ \\
\hline Role overload & .161 & .043 & 3.707 & $* * *$ \\
\hline compulsive passion & .116 & .046 & 2.505 & $* * *$ \\
\hline Perceived social support & .099 & .048 & 2.063 & $* * *$ \\
\hline $\begin{array}{c}\text { compulsive passion } \times \\
\text { Perceived social support }\end{array}$ & -.121 & .044 & -2.780 & $* * *$ \\
\hline $\mathrm{R}^{2}$ & \multicolumn{5}{|c|}{.250} \\
\hline $\mathrm{F}$ & \multicolumn{5}{|c}{9.606} \\
\hline
\end{tabular}

Table 4. The effect of role overload on entrepreneurial burnout at low, medium and high moderating levels

\begin{tabular}{|c|c|c|c|c|c|}
\hline moderator & level & Effect & BootSE & $\begin{array}{c}\text { BootLL } \\
\text { CI }\end{array}$ & $\begin{array}{c}\text { BootUL } \\
\text { CI }\end{array}$ \\
\hline \multirow{2}{*}{$\begin{array}{c}\text { Perceived } \\
\text { social } \\
\text { support }\end{array}$} & $\begin{array}{c}\mathrm{M}-1 \\
\text { SD }\end{array}$ & 0.062 & 0.025 & 0.021 & 0.117 \\
\cline { 2 - 6 } & $\mathrm{M}$ & 0.029 & 0.014 & 0.006 & 0.060 \\
\cline { 2 - 6 } & $\begin{array}{c}\mathrm{M}+1 \\
\text { SD }\end{array}$ & -0.005 & 0.016 & -0.038 & 0.027 \\
\hline
\end{tabular}

We found that the interaction between perceptual support and obsessive passion is significant for entrepreneurial burnout, and it negatively moderates the relationship between obsessive passion and entrepreneurial burnout. It can be found that when the level of perceptual support is low (-1 SD), obsessive passion has a significant negative moderating effect on entrepreneurial burnout (effect size $=0.062, \mathrm{P}<0.01$ ). However, when the level of perceived support was higher $(+1 \mathrm{SD})$, the negative moderating effect of obsessive passion on entrepreneurial burnout was small (effect size $=-0.005, \mathrm{p}>0.05$ ), which indicated that with the increase of the level of perceived support, the influence of obsessive passion on individual entrepreneurial burnout was gradually decreasing.

\subsection{Analysis of research results}

The influence of role overload on entrepreneurial burnout has been paid more and more attention, and how to alleviate entrepreneurial burnout has become a very important issue. In order to solve this problem, based on identity theory and resource conservation theory, combined with the research on compulsive passion and emotional exhaustion, this paper proposes a moderated mediation model to examine the relationship between role overload, compulsive passion and entrepreneurial burnout, as well as the moderating effect of perceived social support. Our results support our hypothesis that obsessive passion does mediate the relationship between role overload and burnout, and perceived social support weakens the effect of obsessive passion on burnout. We get the conclusion that entrepreneurs in order to meet the requirements of the role and expectations will be forced to continue into the entrepreneurial activity, produce a kind of compulsive passion, this keep behavior will be the over-consumption of entrepreneur resources and energy, which produces tired feeling to entrepreneurship, but with the help of family, friends and others support could alleviate the symptoms of burnout of entrepreneurs.

\section{Conclusion}

\subsection{Theoretical significance}

This paper makes many contributions to the study of entrepreneurial burnout. First, the results of this paper show that in order to better understand the generation of entrepreneurial burnout, it is necessary to recognize the importance of role stress in the early stage of entrepreneurship. Existing studies mostly discuss the impact of job requirements, entrepreneurial pressure and social responsibility on entrepreneurial burnout, ignoring the important role overload ${ }^{[16]}$. However, in fact, entrepreneurs have numerous role demands and scarce available resources, so role overload has been identified as a prominent feature that entrepreneurs are different from ordinary employees. From the perspective of identity, we emphasize the difference between entrepreneurial burnout and job burnout in the general work environment. Due to the particularity of entrepreneurial background, entrepreneurs bear multiple role pressures and experience more serious role overload, so they are more likely to feel burnout ${ }^{[2]}$. This provides a new explanatory path for the limited research on entrepreneurial burnout and expands the research on the antecedent variables of entrepreneurial burnout.

Secondly, the study found that compulsive passion played a significant mediating role between role overload and entrepreneurial burnout. We believe that the rigid persistence of entrepreneurs with obsessive passions makes it difficult for them to disengage from their work, and even when they do, they continue to think about their work. This persistence eventually drains them too much of their energy and resources and leads to burnout, burnout of starting a business ${ }^{[17]}$. In the past, a large amount of evidence has shown that passion 
is not only a common feature of entrepreneurs but also a unique emotional experience. More and more studies on passion for work focus on explaining the intermediary mechanism of passion for work. Therefore, it is also very important to study how to trigger entrepreneurs' forced passion and further form entrepreneurial burnout. This study using the theory of identity and resource conservation theory made interpretation: in order to solve the time pressure and facing a lot of promise, entrepreneurs will invest a lot of time and energy in their work and resources, in order to meet the job required by the performance and behavior, in the process of doing so, they gradually develop their compulsive passion ${ }^{[6]}$, this passion is not released, will lead to the conflict between work and other life activities, and produce negative emotions, and increase the likelihood of entrepreneurs through entrepreneurship is tired. Our research shows that environment and personal emotions influence entrepreneurs' attitudes and behaviors, which provides a new theoretical mechanism for explaining how role overload activates obsessive passion and ultimately leads to burnout.

Finally, this study not only explores the role of context in the formation of entrepreneurial burnout, but also considers the moderating role of perceived social support from the perspectives of social help and selfregulation $^{[18]}$. The study found that the emotional help and work resources provided by perceived social support allowed entrepreneurs to reduce rigid work patterns and to stop working when they felt tired or unhappy at work, thus reducing the relationship between compulsive passion and burnout. This solves the problem that the influence mechanism boundary of role overload on entrepreneurial burnout is not clear.

\subsection{Practical significance Research prospects and deficiencies}

Entrepreneurs who have started their own businesses are very clear that they are under a lot of pressure in the process of starting a business, and they are tired physically and mentally, so burnout is inevitable. Finding out the root causes of burnout is the top priority to solve. The revelation of role overload makes us discuss the strategies to deal with entrepreneurial burnout from a new perspective and clarify the specific forms of entrepreneurial pressure of entrepreneurs. Entrepreneurs should realize that their role has many demands and few resources available, and they need to be better prepared to moderate the negative effects of obsessive passions on their happiness. And in the process of starting a business, entrepreneurs can actively seek social support to obtain more resources, selfefficacy and spiritual comfort, to reduce the entrepreneurial burnout. Faced with a lot of pressure in entrepreneurship, entrepreneurs need to adopt a variety of coping strategies to solve the burnout on the road of entrepreneurship. They should combine behavioral exploration with cognitive avoidance. They should not only stay away from pressure, adjust themselves and seek support from others, but also improve their skills, find out action plans and take active actions.

\subsection{Research prospects and deficiencies}

The contribution of this study should be viewed in terms of its limitations. First, the data is collected from across the country, so it is difficult to control for job types and workplaces, and these differences may lead to different views among entrepreneurs. On the other hand, different entrepreneurial policies and government support in different provinces will affect the psychological feelings of entrepreneurs. Nevertheless, the role of human resource systems and other potential moderators should be investigated. Secondly, there may be many antecedent variables affecting entrepreneurial burnout, and this study only considered role overload and compulsive passion. However, we also acknowledge that many exogenous variables (e.g., personality traits, social environment) rooted in other theories may contribute to entrepreneurial burnout. Further research is needed to rule out other explanations. Thirdly, cross-sectional data were used in this study to study the relationship between variables, resulting in inaccurate research conclusions. Our results cannot be generalized to all stages of entrepreneurship, so future research can consider conducting questionnaires on entrepreneurs in different time stages to make the research results more reliable.

\section{References}

1. Maslach, Christina, and M. Leiter. JAP, 93,3(2008).

2. D.Shepherd. Journal of Research in Marketing \& Entrepreneurship, 12,1(2010)

3. De Mol E., Ho V.T., Pollack J.M.,Journal of Small Business Management,56,3(2016).

4. Mueller B.A., Wolfe M.T., Syed I. JBV, 32,3(2017).

5. Lerman M.P., Williams D.W.,Frontiers of Entrepreneurship Research,37,4 (2017).

6. Stroe S, Wincent J, Parida V.,JBR, 90(2018).

7. Vallerand,R.J.,Houlfort,N.Greenwich,CT(Informatio n Age Publishing,2003)

8. Shiyi Z., Shu D., Heng G., Front Psychol, 9(2018).

9. Kong D T., Ho V T.European Journal of Work and Organizational Psychology,27(2018).

10. Sheldon K M, Krieger L S . Behavioral ences \& the Law, 22,2(2010).

11. Rehman A.U., Bhuttah T.M.,You X. Psychology Research and Behavior Management, 13(2020).

12. Gottlieb B.H.,Bergen A.E.JPR,69,5(2010).

13. Stephan, U.AMP,32,2(2018).

14. Peterson M. F., Smith P. B., Akande A. AMJ, 38,2(1995).

15. Zimet, G. D., Dahlem, N. W.,et al.JPA,52,1(1988).

16. Stephan, U. Academy of Management Perspectives, 32,3(2018).

17. Mueller B.A., Wolfe M.T., Syed, I. JBV, 32,3(2017). 
18. Shantz A, Arevshatian L, Alfes K. Human Resource Management Journal,26,2(2016). 